\title{
Synthesis of $S$-(28a-homobetulin-28a-yl) thiophosphate, thiophosphonate, and thiophosphinate
}

\author{
Katarzyna Sidoryk,, a,b Piotr Cmoch, ${ }^{a}$ Lucie Rárová,c Jana Oklešt'ková, ${ }^{d}$ \\ Zbigniew Pakulski,*,a Miroslav Strnad,*,d
}

${ }^{a}$ Institute of Organic Chemistry, Polish Academy of Sciences, Kasprzaka 44/52, 01-224

Warsaw, Poland;

${ }^{\mathrm{b}}$ Pharmaceutical Research Institute, Rydygiera 8, 01-793 Warsaw, Poland

${ }^{c}$ Department of Chemical Biology and Genetics, Centre of the Region Haná for

Biotechnological and Agricultural Research, Palacký University, Šlechtitelů 27, 78371

Olomouc, Czech Republic

${ }^{\mathrm{d}}$ Laboratory of Growth Regulators, Centre of the Region Haná for Biotechnological and Agricultural Research, Institute of Experimental Botany ASCR \& Palacký University, Šlechtitelů 27, 78371 Olomouc, Czech Republic

Email: pakul@icho.edu.pl

\section{Supplemental Materials}

Table S 1. IC $50(\mu \mathrm{M})$ values obtained from Calcein AM assays with the tested cancer and normal cell lines; means \pm SD obtained from three independent experiments performed in triplicate. Betulinic acid (11) was used as a positive control.

\begin{tabular}{|c|c|c|c|c|c|}
\hline & & \multicolumn{4}{|c|}{$\mathrm{IC}_{50}[\mu \mathrm{M}]$} \\
\hline Comp. No. & $\mathrm{R}$ & CEM & MCF7 & HeLa & BJ \\
\hline 2 & $-\mathrm{OSO}_{2} \mathrm{CH}_{3}$ & $16.8 \pm 0.6$ & $41.4 \pm 1.7$ & $25.1 \pm 1.7$ & $>50$ \\
\hline 3 & $-\mathrm{SCN}$ & $13.7 \pm 4.9$ & $7.8 \pm 1.7$ & $4.7 \pm 0.3$ & $18.0 \pm 0.8$ \\
\hline 4 & $-\mathrm{SP}(\mathrm{O})\left(\mathrm{OC}_{2} \mathrm{H}_{5}\right)_{2}$ & $>50$ & $>50$ & $>50$ & $>50$ \\
\hline 9 & $-\mathrm{SP}(\mathrm{O})\left(\mathrm{C}_{6} \mathrm{H}_{5}\right)_{2}$ & $>50$ & $>50$ & $>50$ & $>50$ \\
\hline 10 & $-\mathrm{SP}(\mathrm{O})\left(\mathrm{C}_{6} \mathrm{H}_{5}\right)\left(\mathrm{OC}_{2} \mathrm{H}_{5}\right)$ & $>50$ & $>50$ & $>50$ & $>50$ \\
\hline 11 & - & $40.0 \pm 2.8$ & $>50$ & $47.6 \pm 1.9$ & $>50$ \\
\hline
\end{tabular}




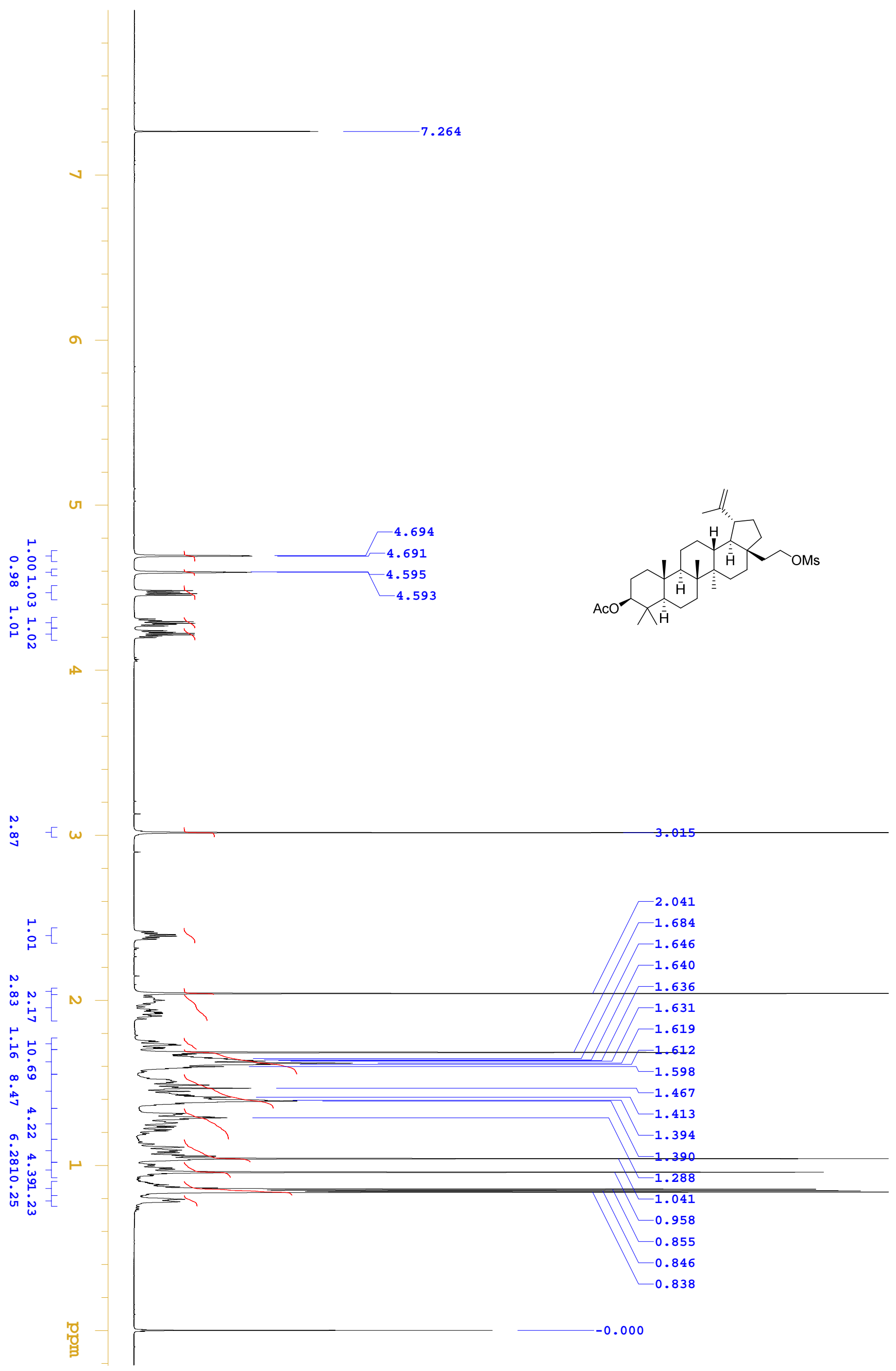




$$
\mid
$$




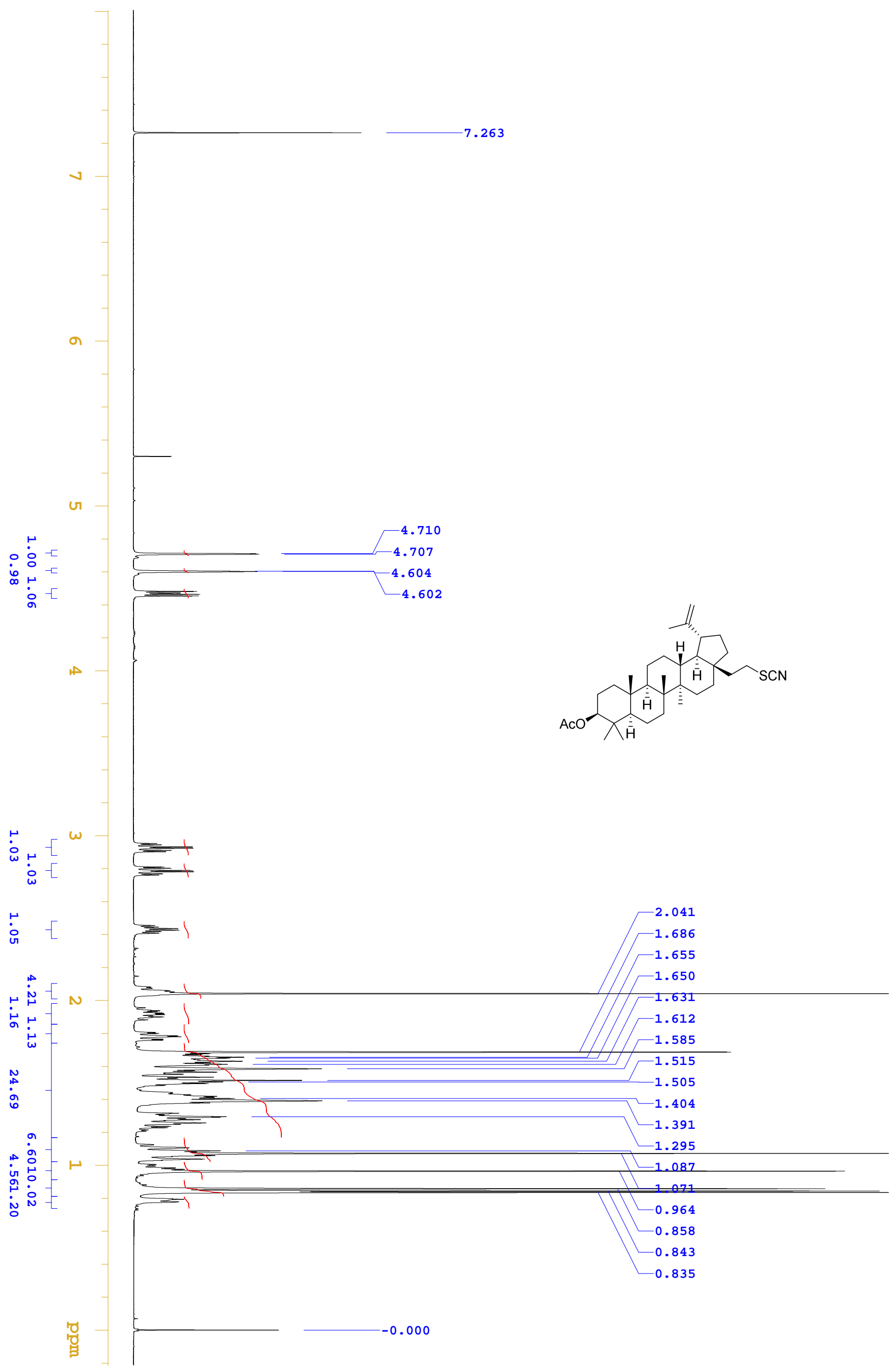




$$
b
$$




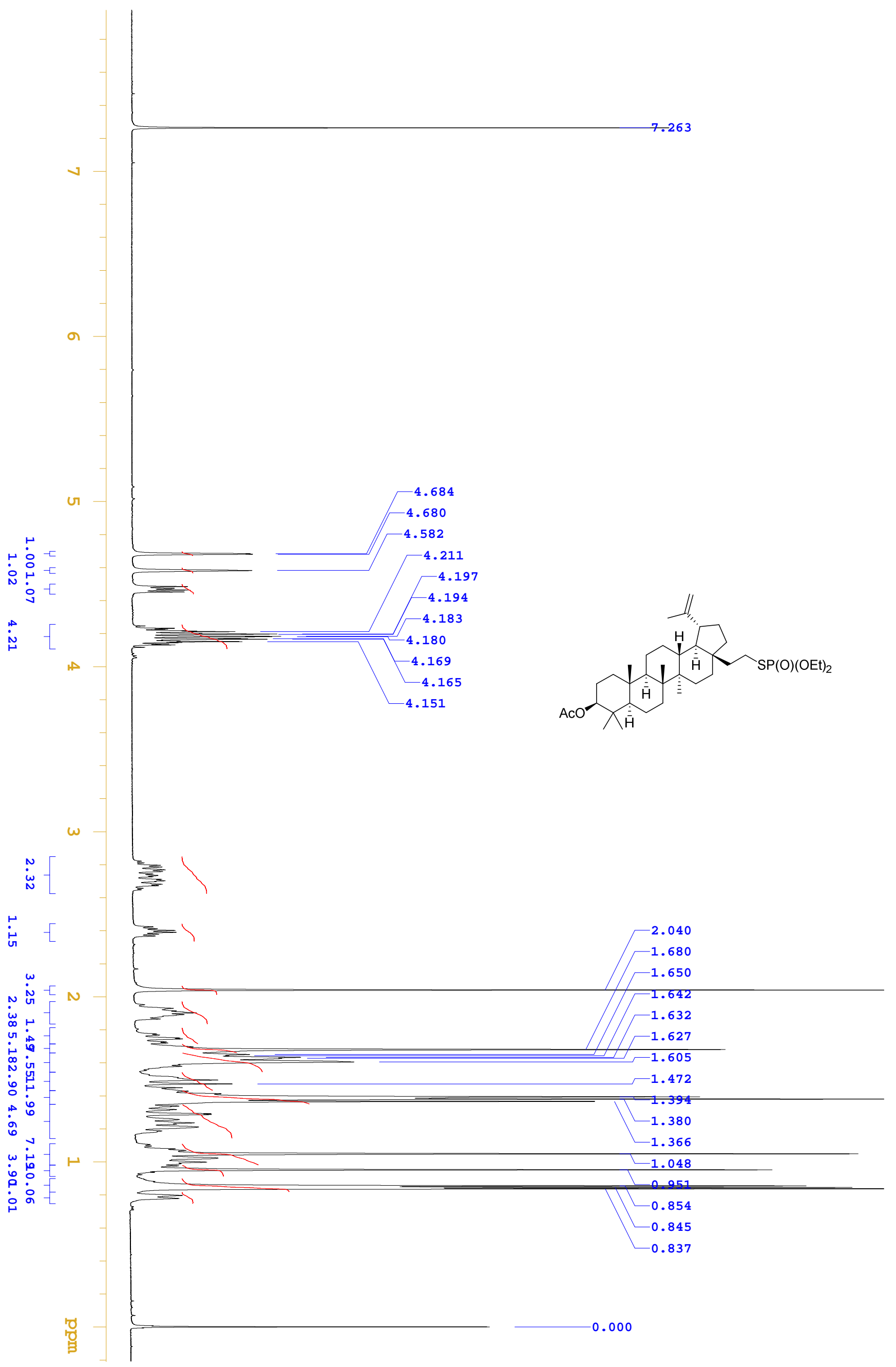



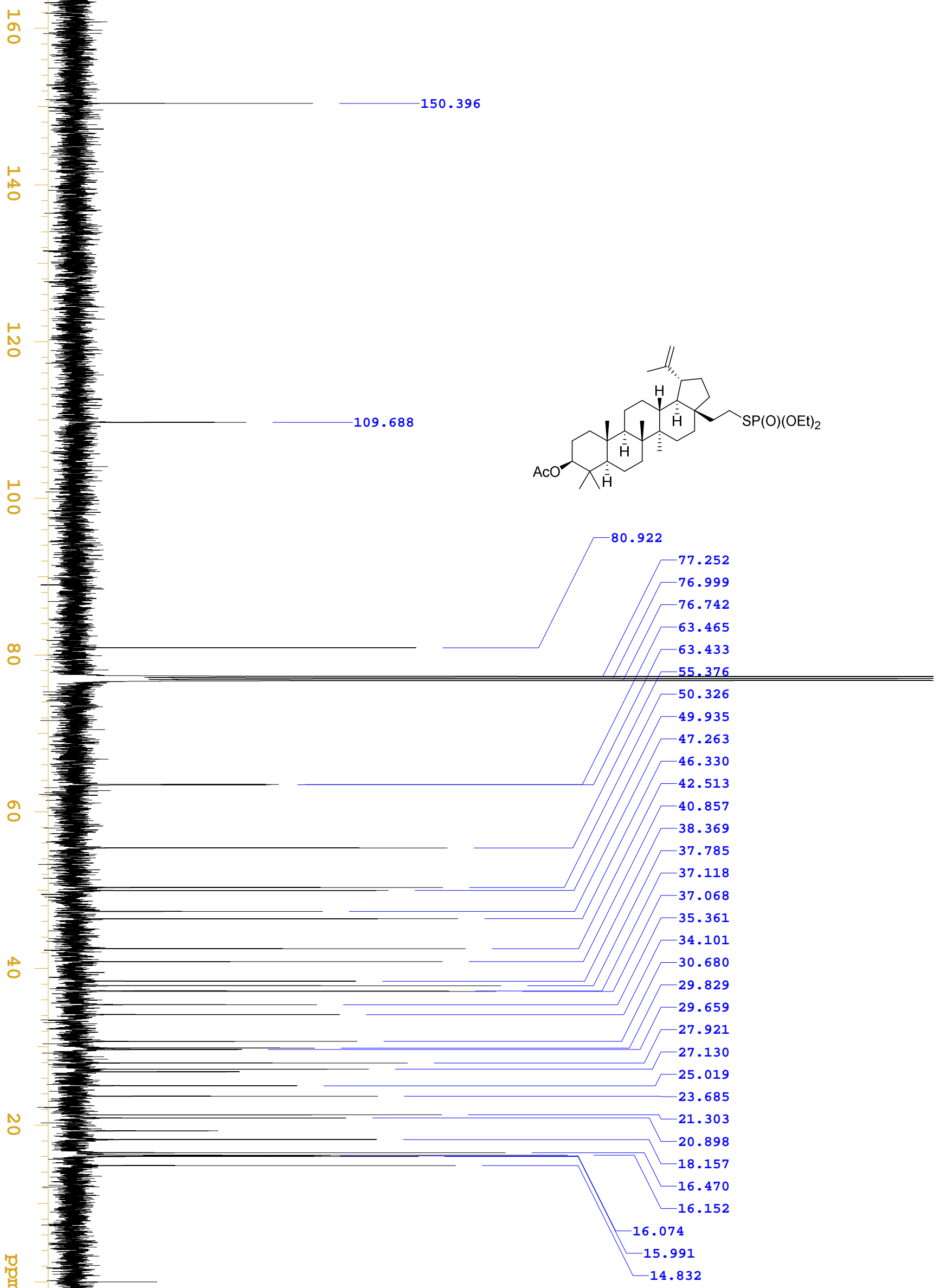


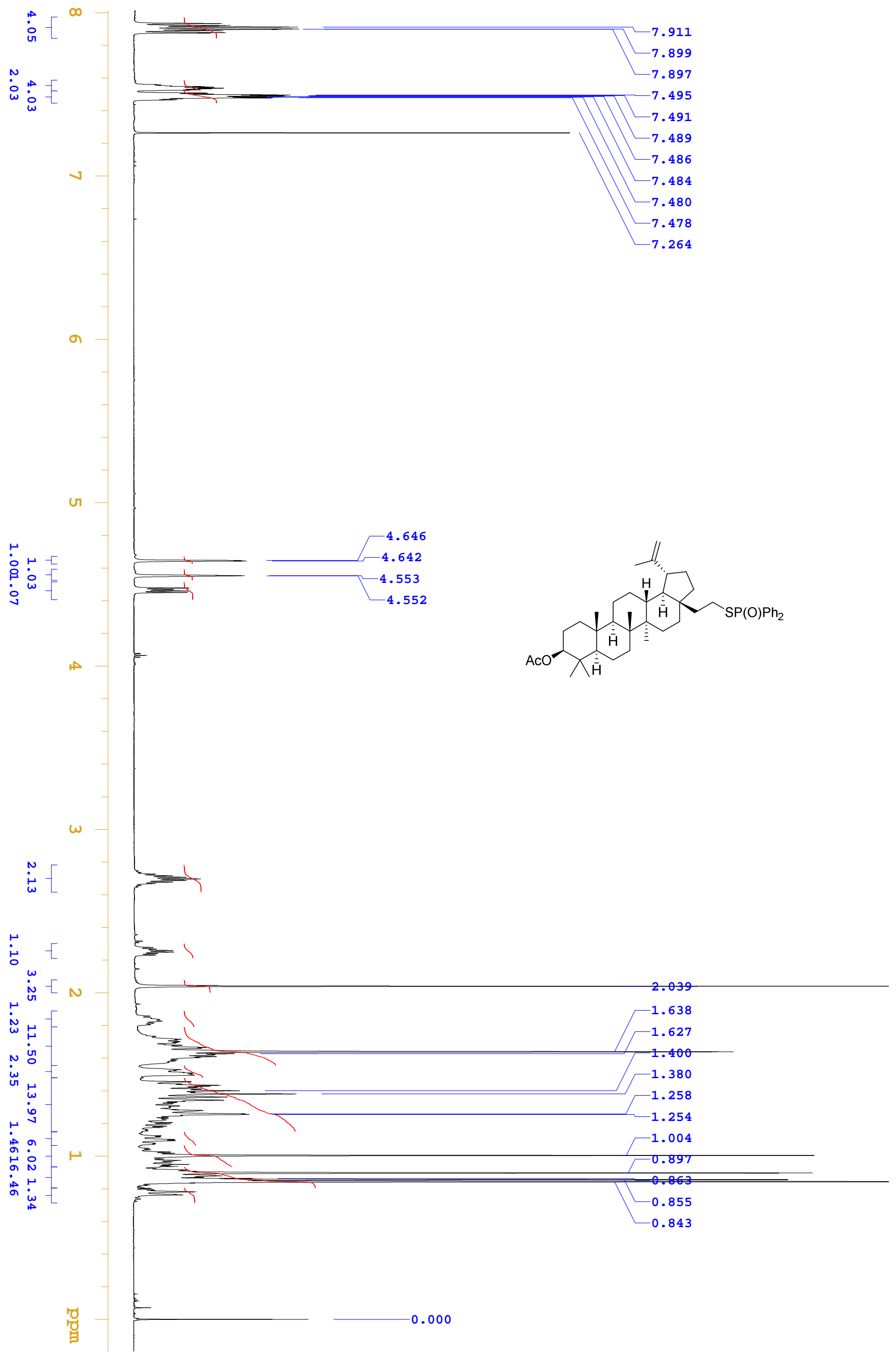




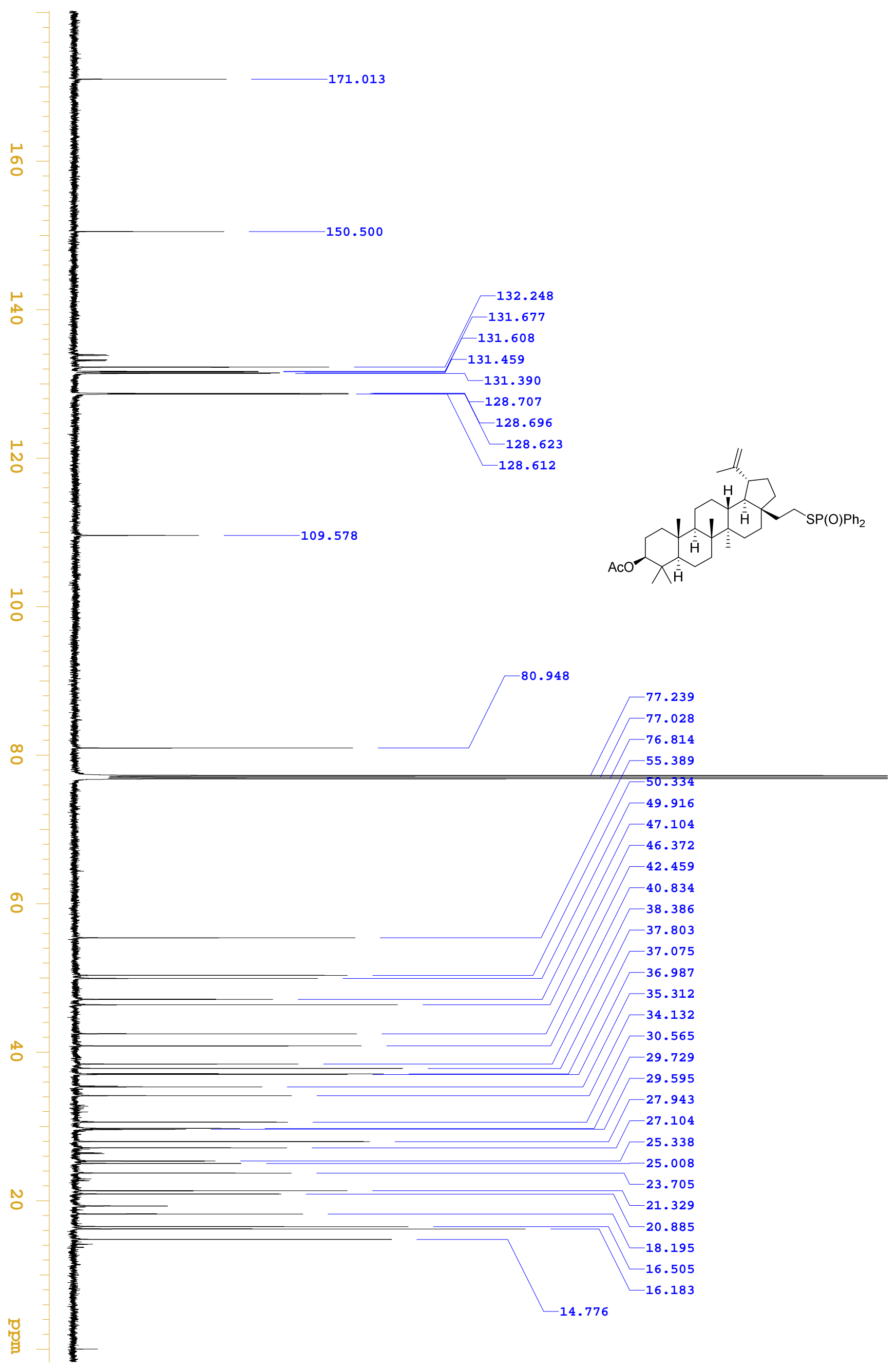




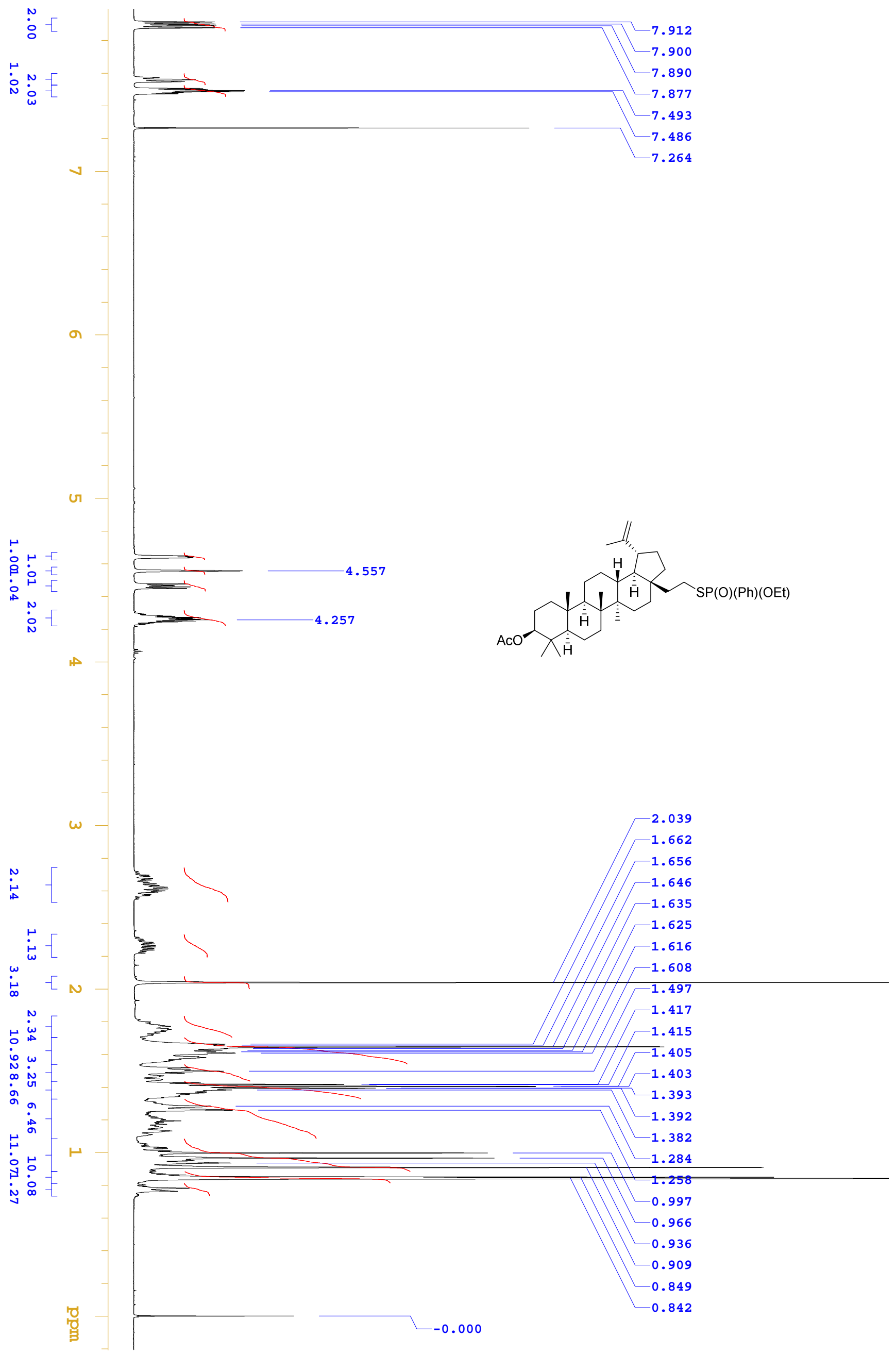




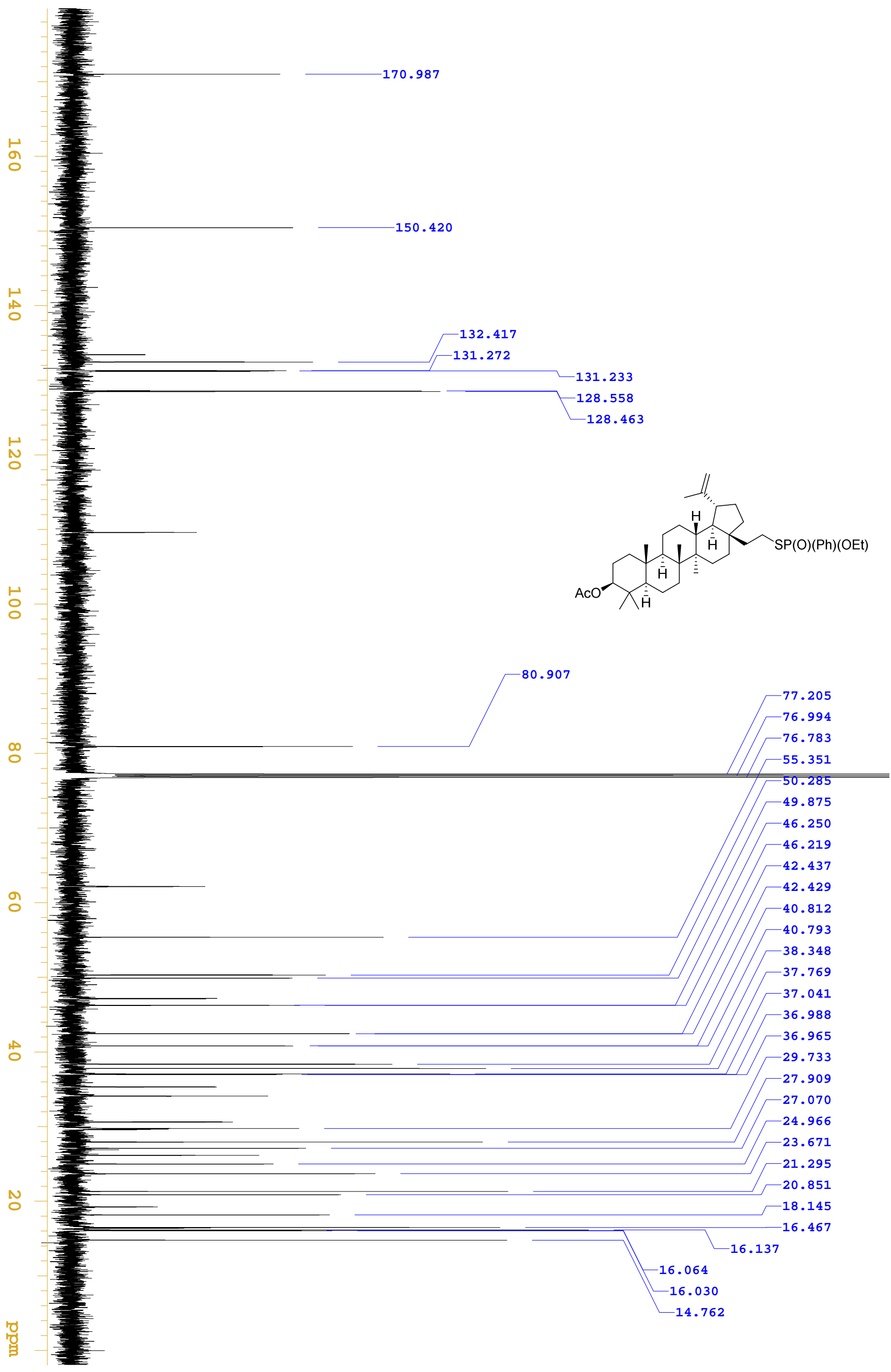




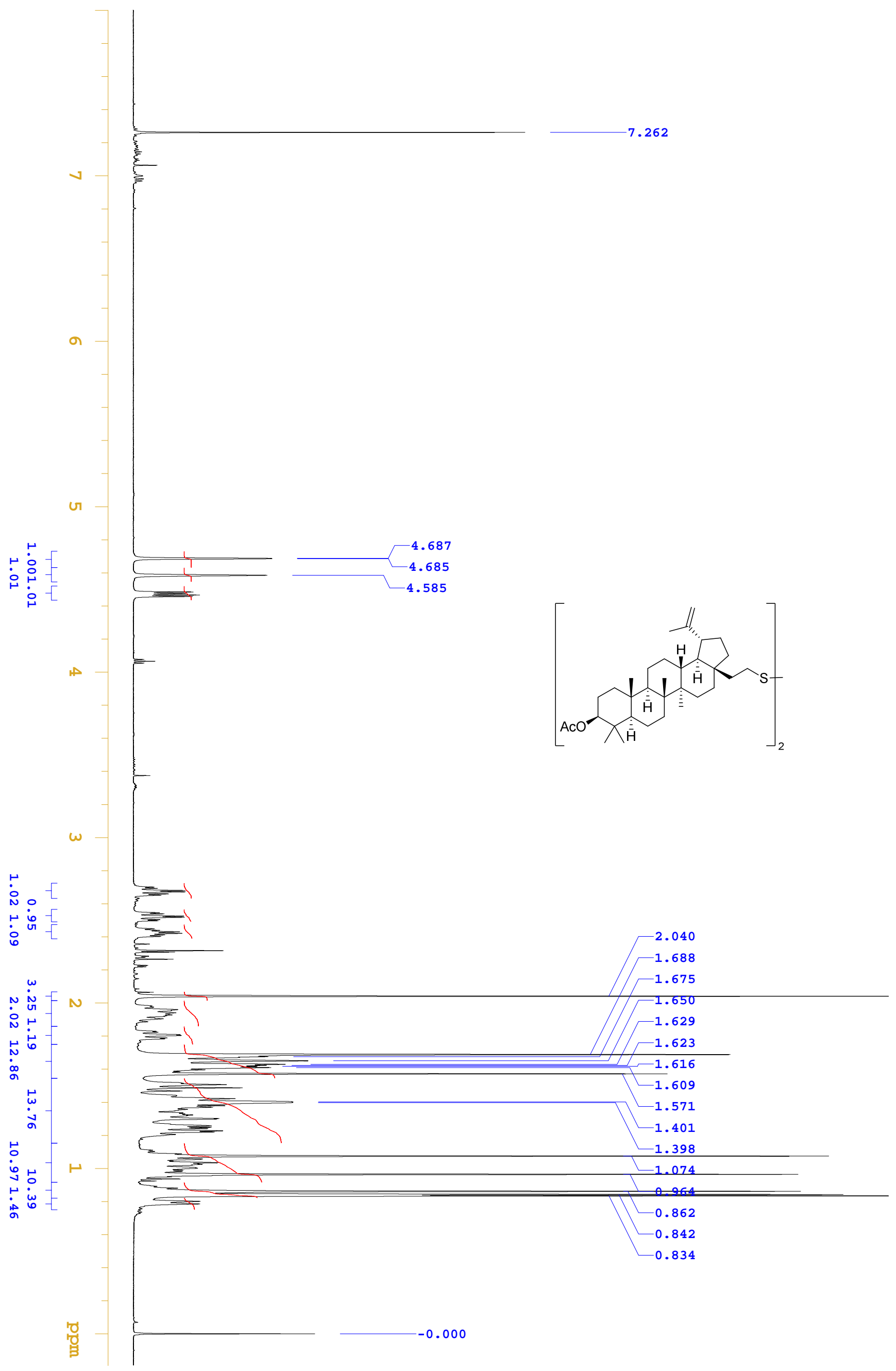




$$
\mid
$$

